\title{
LA SUSPENSION DE LAS LICENCIAS DE OBRAS
}

351.778 .511

por

José-María Boquera Oliver

SUMARIO: I. INTRODUCCION. - II. LA SUSPENSION DE LOS EFECTOS DEL ACTO ADMINISTRATIVO. - III. LA SUSPENSION DE LOS EFECTOS DE LAS LICENCIAS DE OBRAS. IV. LA SUSPENSION DE LOS EFECTOS DE LAS LICENCIAS DE OBRAS DESPUES DE HABER TRANSCURRIDO UN AÑO CONTADO A PARTIR DE SU NOTIFICACION O PUBLICACION. V. LAS AUTORIDADES COMPETENTES PARA DECIDIR LA SUSPENSION DE LAS LICENCIAS.-VI. RESPONSABILIDAD ADMINISTRATIVA DE QUIENES PARTICIPEN EN EL OTORGAMIENTO DE UNA LICENCIA QUE CONSTITUYA MANIFIESTAMENTE INFRACCION URBANISTICA GRAVE.-VII. RESPONSABILIDAD POR LOS DAÑOS O PERJUICIOS QUE OCASIONE LA SUSPENSION DE LOS EFECTOS DE LAS LICENCIAS.

\section{INTRODUCCION}

La regulación por la Ley del Suelo y el Reglamento de Disciplina Urbanística de la suspensión de las licencias de obras suscita muchos e importantes problemas de interpretación. Para estudiar esta regulación con la suficiente perspectiva recordaré, antes de entrar en su examen, algunas ideas sobre la suspensión de la eficacia de los actos administrativos, pues las licencias de obras, obvio es decirlo, son ac- 
tos administrativos y su suspensión será sólo una pequeña parte del capítulo que en la teoría general del acto administrativo se dedica a la paralización temporal de su eficacia.

\section{LA SUSPENSION DE LOS EFECTOS DEL ACTO ADMINISTRATIVO}

Las Administraciones públicas mandan, y mandan porque, para satisfacer los fines públicos, pueden crear e imponernos a los administrados obligaciones y otorgarnos derechos. Este poder de mando no es absoluto, incondicionado, sino que está subordinado al Derecho u Ordenamiento jurídico. Las Administraciones públicas deben actuar conforme a las normas que integran el Ordenamiento jurídico y se presume, con presunción iuris tantum, es decir, destructible, que siempre lo hacen así. Los destinatarios de los efectos de un acto administrativo pueden, pues, demostrar que dicha presunción es falsa. Pero mientras no demuestren tal cosa, o, mejor, mientras quien tenga competencia para ello no declare que dicha presunción no es real, el acto administrativo producirá todos sus efectos.

Se comprende fácilmente que, si se presume que los actos administrativos atienden fines públicos de acuerdo con la legalidad, no resulte posible suspender o paralizar temporalmente sus efectos $y$, consecuentemente, la realización, la efectividad, de dichos efectos. La suspensión de la eficacia de un acto administrativo, en principio, perjudica, sin justificación, la atención de los fines públicos.

No podemos ni siquiera pensar que cuando se sospecha que un acto administrativo es ilegal cabe la suspensión de su eficacia, pues una sospecha, e incluso la convicción sobre su ilegalidad manifestada por quien no tiene competencia para juzgar a los actos administrativos, no puede destruir una presunción legal. Si quien tiene la facultad de hacerlo declara que el acto no es conforme a Derecho, cesarán sus efectos jurídicos y carecerá de sentido la paralización de los mismos por un cierto tiempo. La imposibilidad de paralizar temporalmente el cumplimiento de las obligaciones y el ejercicio de los derechos, de los actos administrativos, es una consecuencia lógica de la presunción iuris tantum de legalidad que les caracteriza. En principio, no puede, pues, suspenderse la eficacia de esta clase de actos jurídicos.

Sin embargo, una cosa es la lógica y otra las exigencias de la rea- 
lidad y, en algunas ocasiones, la aplicación de las consecuencias lógicas de una categoría jurídica puede ser perjudicial para el desenvolvimiento de la vida de los hombres. Cuando así ocurre, resulta necesario establecer las indispensables excepciones para evitar los perjuicios que la total aplicación de las reglas lógicas puede causarnos.

A la regla de la imposibilidad de suspender la ejecución de los efectos del acto administrativo, la realidad le impuso, hace ya mucho tiempo, una excepción: la de que su ejecución ocasione un daño o perjuicio de imposible reparación (1). (Por ejemplo, si se ordena la demolición de un monumento y después se anula esta orden, el monumento ya no podrá recuperarse.) Esta excepción sólo podían hacerla valer los particulares al recurrir contra los actos administrativos. La autoridad administrativa o el órgano jurisdiccional que conocía del recurso podía decidir la paralización de la ejecución del acto si consideraba que de ésta podía derivarse un daño de imposible reparación en el supuesto de que, posteriormente, estimara el recurso por considerar el acto ilegal. Para acordar la suspensión se exigía, además, una caución suficiente con la que poder compensar los perjuicios que la paralización del acto causaría a los fines públicos. Como puede apreciarse, se trataba de una causa de excepción a la regla de la no suspensión de los efectos del acto administrativo muy justificada y cuya aplicación se rodeaba de grandes precauciones.

Más tarde se pensó que justificar la excepción sólo por la imposibilidad de la reparación del daño o perjuicio, es decir, tomar en cuenta únicamente el caso límite, resultaba insuficiente y que también convenía admitir la suspensión cuando la reparación del daño fuera dificil (2).

En la actualidad, la imposible o difícil reparación de los daños o perjuicios que puede ocasionar la ejecución del acto administrativo es la única causa que, con carácter general, sirve de excepción a la regla de la no suspensión de los efectos del acto administrativo. Excepción-insisto-que sólo puede aplicarse si se recurre en vía ad-

(1) Artículo 100 de la Ley de la Jurisdicción Contencioso-administrativa de 22 de junio de 1894: «Los Tribunales de lo Contencioso-administrativo podrán acordar, oído el Fiscal, la suspensión de las resoluciones reclamadas en la vía contenciosa, cuando la ejecución pueda ocasionar daños irreparables, exigiendo fianza de estar a las resultas al que hubiere pedido la suspensión".

(2) Artículo 122, 2, de la Ley de la Jurisdicción Contencioso-administrativa de 27 de diciembre de 1956 y artículo 116 de la Ley de Procedimiento. Criterio opuesto del artículo" 122 de la Ley de la Jurisdicción se contiene en el artículo $7 .^{\circ}, 2,3,4,5$ y 6 de la Ley 62/1978, de 26 de diciembre, sobre protección jurisdiccional de los derechos fundamentales de la persona. 
ministrativa o jurisdiccional contra el acto y se adoptan las debidas garantías (3).

Si no se da claramente la circunstancia prevista para que tenga lugar la excepción, no podrá aplicarse la norma excepcional, pues esta clase de normas deben interpretarse restrictivamente. En caso de duda debemos inclinarnos a favor de la no suspensión del acto administrativo.

La Sentencia de 27 de septiembre de 1971, Sala Cuarta (Rep. Aranzadi núm. 4.000), dice "que con tales enunciados (los de los artículos 101, en relación con el 44 de la Ley de Procedimiento administrativo..., y artículo 122 de la Ley de la Jurisdicción Contenciosoadministrativa) (los preceptos que recogen la repetida regla y su excepción) se muestra que la suspensión de la ejecución constituye medida de excepción de la regla general preceptiva indicada", $\mathrm{y}$, por tanto, aquella tiene carácter restringido.

Por motivos muy diferentes a las exigencias de la realidad, desde la Ley municipal de 1877 se permitió que autoridades gubernativas suspendieran los acuerdos de los Municipios e impidieran su ejecución. El motivo principal de la suspensión gubernativa de acuerdos municipales, cuya ejecución no producía daños de imposible o difícil reparación, fue, inicialmente, defender la competencia del Estado frente a posibles extralimitaciones de las Entidades locales. En esta idea insistió mucho MaURa al defender sus proyectos de Ley Municipal de 1903 y 1907. Dicha causa de excepción al principio de no suspensión de los efectos del acto administrativo tiene escasa justificación-para no decir que carece totalmente de justificación-, porque una extralimitación de la competencia equivale a una infracción de la ley que delimita dicha competencia y corresponde al Juez enjuiciar y, en su caso, destruir a los actos viciados de ilegalidad. Además, para resolver los conflictos de competencia hay previstos, o pueden establecerse, procedimientos especiales mucho mejores que el que sea una autoridad de una de las Administraciones públicas en conflicto-el Alcalde es el Delegado del Gobierno en el término municipal y el Gobernador civil lo es en la Provincia-la que, al menos inicialmente, dé una solución al conflicto. Pero, sin entrar ahora a exponer mayores detalles sobre esta cuestión, y sin referirme a la

(3) También cabe solicitar la suspensión de la ejecución del acto impugnado, si se recurre en vía administrativa, cuando la impugnación se fundamenta «en alguna de las causas de nulidad de pleno derecho previstas en el artículo 47 » de la Ley de Procedimiento administrativo (art. 166 LP). 
evolución seguida en esta materia (4), la vigente Ley de Régimen local, en su artículo 362, impone a los Presidentes de las Corporaciones locales (Alcaldes y Presidentes de Diputación Provincial) y, en defecto de éstos, a los Entes Autonómicos y Preautonómicos y a los Gobernadores civiles (art. 365, LRL), el deber de suspender los acuerdos locales en los casos siguientes:

1. Cuando recaigan en asuntos que, según las leyes, no sean de su competencia.

2. $\quad$ Cuando constituyan delito.

3. Cuando sean contrarios al orden público.

4. Cuando constituyan infracción manifiesta de las leyes.

«La suspensión habrá de decretarse-dice la Ley-dentro de los tres dias siguientes a aquel en que se hubiera tomado el acuerdo".

Consecuentemente, los actos administrativos locales son susceptibles de suspensión no sólo cuando su ejecución produzca daños y perjuicios de imposible o difícil reparación, y mediante la interposición de recursos administrativos o jurisdiccionales, sino también en los casos que acabamos de recordar y a iniciativa de las autoridades enumeradas. Y, como se habrá comprobado, salvo el caso tercero-temor de que con ellos se altere el orden público, lo que podría ocasionar daños de imposible o difícil reparación-, son supuestos de defensa de la legalidad. En consecuencia, para aplicar los números $1 .^{\circ}, 2 .^{\circ}$ y $4 .^{\circ}$ del artículo 362 de la Ley de Régimen local, los Presidentes de las Corporaciones, los órganos de los Entes Autonómicos y Preautonómicos o los Gobernadores civiles formulan juicios y hacen afirmaciones sobre la legalidad de los actos administrativos locales. Afirmaciones que inciden sobre la consecuencia natural de la presunción iuris tantum de legalidad de los actos administrativos: la continuidad de sus efectos jurídicos.

La Ley de Régimen local contiene, pues, un segundo grupo de motivos que permiten la suspensión de los efectos de los actos ad. ministrativos, pero únicamente de los actos administrativos nacidos de las Administraciones locales.

Pero no terminan con la Ley de Régimen local las excepciones a la regla de la no suspensión de los efectos de los actos administrativos si éstos proceden de los Municipios.

(4) Puede verse Boquera Oliver. I. M.": "La facultad gubernativa de suspensión e impugnación de acuerdos locales manifiestamente ilegales», Revista de Administración Pública, núm. 36 (1961), págs. 109-30. 
La Ley sobre Régimen del Suelo y Ordenación Urbana de 9 de abril de 1976 ha ampliado las posibilidades de suspensión de los acuerdos municipales si éstos son urbanísticos. Su artículo 224, 1, dice: "Los acuerdos municipales que constituyeren infracción manifiesta de normas urbanísticas vigentes podrán ser dejados en suspenso dentro del año siguiente a su notificación o publicación, cuando ésta fuere preceptiva, por los órganos y con el procedimiento y efectos que se prevén en el artículo 186, adoptándose simultáneamente las medidas pertinentes para la efectividad de las disposiciones vulneradas».

Este artículo de la Ley del Suelo amplía, para los acuerdos municipales en materia de urbanismo, de una parte, lo dispuesto por el número $4 .^{\circ}$ del artículo 362 de la Ley de Régimen local, y, de otra, el plazo para poderlos dejar en suspenso. El artículo $362,4 .^{\circ}$, de la Ley de Régimen local se refiere a la infracción manifiesta de «leyes», y el 224 de la Ley del Suelo, a la infracción manifiesta de «normas urbanísticas». Esta última expresión comprende a las leyes urbanísticas, a los reglamentos de este carácter, a los planes de ordenación urbana, programas de actuación, etc. En realidad, en este punto, la Ley del Suelo, más que modificar el número $4 .^{\circ}$ del artículo 362 de la Ley de Régimen local, clarifica su interpretación, pues la jurisprudencia, en reptidas ocasiones, entiende ampliamente el término «leyes» hasta comprender en él a toda disposición jurídica (5).

\section{LA SUSPENSION DE LOS EFECTOS DE LAS LICENCIAS DE OBRAS}

Siendo en la mayor parte de los casos las licencias de obras acuerdos municipales urbanísticos, puesto que «la competencia para otorgar las licencias corresponderá a los Ayuntamientos, salvo en los casos previstos por la Ley del Suelo»(6), el artículo 362 de la Ley de Régimen local, en sus números $10^{\circ}, 2 .^{\circ}$ y $3 .^{\circ}$, y el artículo 224,1 , de la Ley del Suelo, ofrecen al Alcalde muchas posibilidades de suspender la eficacia de aquéllas. Pueden hacerlo cuando las otorgue el Ayuntamiento sin corresponderle; si constituyen delito, o fueren contrarias al orden público, y también si las consideran manifiestamente contrarias a las leyes, reglamentos, planes de ordenación

(5) «La palabra Ley debe entenderse en un sentido amplio equivalente a norma jurídica» (Sentencias de 17 de noviembre de 1966, Sala 4.", y de 3 de mayo de 1979).

(6) Artículo 179, en relación con el artículo 178, 1, de la LS. 
urbana, programas de actuación urbanística y, en su caso, normas complementarias y subsidiarias del planeamiento (7). En los tres primeros casos el plazo para decidir la suspensión será de tres días desde la adopción del acuerdo de concesión, y en el último, de un año, contado a partir de la notificación o publicación de aquéllas.

Sin embargo, la Ley del Suelo, en su artículo 186, 1, al que se refiere el citado artículo 224 de la misma Ley, dice: «El Alcalde dispondrá la suspensión de los efectos de una licencia $u$ orden de ejecución $\mathrm{y}$, consiguientemente, la paralización inmediata de las obras iniciadas a su amparo, cuando el contenido de dichos actos administrativos constituya manifiestamente una infracción urbanistica grave». ¿Este precepto ofrece al Alcalde otra posibilidad, una posibilidad más, de suspender actos administrativos urbanísticos, que se añade a las que hasta ahora hemos visto que tenía, o es la única posibilidad de que aquél dispone para suspender los efectos de las licencias de obras? Como se habrá apreciado, los artículos 362 de la Ley de Régimen local y el artículo 224 de la Ley del Suelo se refieren, respectivamente, a acuerdos locales y a acuerdos municipales y, en cambio, el artículo 186 de la Ley del Suelo se refiere única y exclusivamente a las licencias y a las órdenes de ejecución de obras. Además, para poder suspender estas clases de actos administrativos exige una causa distinta, y me parece que de mucha más entidad, que las enumeradas en los artículos 362 de la Ley de Régimen local y en el artículo 224, 1, de la Ley del Suelo.

El artículo 186, 1, de la Ley del Suelo sólo es aplicable cuando el contenido de las licencias constituya manifiestamente una infracción urbanistica grave. Pudiera, pues, pensarse que este precepto contiene el régimen de suspensión de las licencias de obras y que éstas sólo pueden suspenderse si concurren las circunstancias que el mismo establece. Si apenas hay unas pocas palabras más en este precepto que en el artículo 224 de la misma Ley, como después veremos, entre ambos existen profundas diferencias. Por esta razón, primordialmente, pienso que el artículo 186, 1, de la Ley del Suelo es una posibilidad distinta, otra posibilidad más, de suspender licencias de obras, que se añade a las que los artículos 362 de la Ley de Régimen local y el artículo 224 de la Ley del Suelo ofrecen a los Alcaldes y que hay que cohonestar con éstas. El artículo 186 de

(7) Las licencias de obras se presumen otorgadas de acuerdo con las previsiones de la Ley del Suelo, de los planes de ordenación urbana y programas de actuación urbanística y, en su caso, de las normas complementarias y subsidiarias del planeamiento (art. 178, 2, de la LS) y dirigidas a alcanzar el fin que dichas normas tratan de conseguir: el ordenado desarrollo y transformación de las ciudades. 
la Ley del Suelo no es el precepto que contiene el régimen de suspensión de las licencias de obras, sino uno de los preceptos que establecen dicho régimen. Este se diversifica en función de las causas de suspensión de las licencias y también, y en relación con las causas legales de suspensión, por los plazos dentro de los cuales la suspensión puede acordarse.

Creo que las causas de suspensión de las licencias de obras y los plazos para decidir dicha suspensión pueden resumirse así:

A) El Alcalde, dentro del plazo de tres dias siguientes a aquél en que se hubiera otorgado una licencia, puede suspenderla:

1. Cuando, según las leyes, no sea competencia del Ayuntamiento el otorgarla.

2. Cuando constituya delito.

3. Cuando sea contraria al orden público.

4. Cuando constituyan infracción manifiesta de las leyes (artículo 362 de la LRL).

B) El Alcalde, dentro del año siguiente a la notificación o publicación de la licencia, cuando ésta fuere preceptiva, puede suspenderla si constituye infracción manifiesta de normas urbanísticas (artículo 224, 1, de la LS).

C) El Alcalde, después de transcurrido el año siguiente a la notificación o publicación de la licencia y hasta que se termine la obra amparada por ésta, podrá suspender la eficacia de la misma si su contenido constituye una infracción urbanistica grave (art. 186, 1, de la LS).

Podemos añadir que terminada la obra ya no se puede suspender la licencia, pero sí se puede revisar, de conformidad con lo que dispone el artículo 187 de la Ley del Suelo. Una cosa es suspender la licencia y otra revisarla. Pero esta cuestión ya nos lleva más allá del tema que nos hemos propuesto estudiar.

\section{LA SUSPENSION DE LOS EFECTOS DE LAS LICENCIAS DE OBRAS DESPUES DE HABER TRANSCURRIDO UN AÑO CONTADO A PARTIR DE SU NOTIFICACION O PUBLICACION}

Volviendo al objeto de nuestro análisis, lo más importante, para no equivocarse-pues en estas cuestiones una equivocación puede resultar muy cara, en el sentido más literal de la expresión-, es 
averiguar cuándo el Alcalde puede suspender una licencia, y paralizar la obra que aquélla ampara, después de transcurrido el año contado a partir de su notificación o publicación. Puede decirse que decidir la suspensión de una licencia dentro del plazo de un año, contado a partir de su notificación o publicación, no entraña demasiada dificultad, pues la interpretación y aplicación de las normas que la regulan no resulta particularmente difícil. Además, se tiene ya una buena experiencia sobre ello, porque el artículo 224 de la Ley del Suelo es un precepto casi idéntico al artículo $362,4 .^{\circ}$, de la Ley de Régimen local. En cambio, el artículo 186, 1, de la Ley del Suelo es una novedad de esta Ley, y su interpretación tiene algunas dificultades. Para intentar entenderlo acertadamente conviene compararlo con el repetidamente citado artículo 224.

El artículo 224, 1, de la Ley del Suelo dice-para el supuesto de que no haya transcurrido el año-que pueden suspenderse los acuerdos municipales, y entre ellos las licencias, si constituyen «infracción manifiesta de normas urbanísticas vigentes".

El artículo 186, 1, de la misma Ley dice-para el supuesto de que ya haya transcurrido un año-que puede y debe suspenderse la licencia cuando su "contenido... constituya manifiestamente una infracción urbanistica grave».

Lo primero que debo hacer notar es que el artículo 224 se refiere a los actos o acuerdos municipales en su totalidad; por tanto, también al acto de licencia en su totalidad, mientras que el 186, 1, se refiere a uno solo de los elementos del acto de licencia, a su contenido. Los acuerdos municipales, como todos los actos administrativos, están constituidos por la causa, la voluntad, la forma, el contenido y el fin. Cada uno de estos elementos puede acomodarse o no acomodarse a las normas urbanísticas vigentes. Si no se acomoda a ellas, sino que las infringe, el acuerdo será ilegal. La ilegalidad o el vicio en la causa de la licencia de obras, en el procedimiento de su preparación o de la formación de la voluntad, en la voluntad misma, en la forma de exteriorizarse, en su contenido y en su fin, puede, si es manifiesto, justificar la suspensión de la eficacia de aquélla siempre que no haya transcurrido un año desde su notificación o publicación. Pero si ha transcurrido un año a partir de su notificación o publicación, únicamente cuando el elemento contenido de la licencia de obras constituye manifiesta infracción urbanística grave puede y debe aquélla suspenderse. El contenido del acto administrativo son sus efectos jurídicos. Lo que solemos llamar el condicionado de la 
licencia; las obligaciones que impone a su destinatario y los derechos que le declara.

En segundo lugar, el artículo 224, 1, de la Ley del Suelo habla de «infracción... de normas urbanísticas», mientras que su artículo 186,1 , se refiere a «infracción urbanistica». Infringir normas urbanísticas significa contradecirlas, no respetarlas. La licencia de obras infringe normas urbanísticas cuando se adopta sin acomodarse a las mismas o en contra de las mismas. En cambio, una infracción urbanística es una especie de falta administrativa.

La infracción de normas jurídicas no constituye por sí sola falta. La infracción de normas equivale a antijuricidad, pero la antijuricidad no siempre es una falta. La infracción de normas urbanísticas no es en todo caso una infracción urbanística, y lamento que la Ley del Suelo no haya sido más expresiva. La Ley del Suelo, en su artículo 225, declara que «la vulneración de las prescripciones contenidas en esta Ley o en los Planes, Programas, Normas y Ordenanzas (antijuricidad) tendrán la consideración de infracciones urbanísticas y llevarán consigo la imposición de sanciones a los responsables..." (responsabilidad que parece implicar culpabilidad y punibilidad). Me parece que el llevar consigo la imposición de una sanción no es sólo la consecuencia de las faltas, sino uno de sus elementos definidores. Sólo se imponen sanciones a quienes incurren en faltas. La infracción urbanística se sanciona porque es una falta administrativa. Para que una infracción o vulneración de normas urbanísticas sea una infracción urbanística será necesario que dicha infracción o vulneración sea sancionable, y para que sea sancionable resultará imprescindible que la vulneración esté tipificada como falta y sea imputable a un sujeto responsable. El artículo 53, 1, del Reglamento de Disciplina Urbanística precisa un poco, sólo un poco más, la noción de infracción urbanística contenida en la Ley del Suelo, pues dice que «constituye infracción urbanística toda vulneración de las prescripciones contenidas en la Ley del Suelo o en los Planes, Programas, Normas y Ordenanzas, sujeta a sanción (punibilidad), conforme a lo determinado en el presente Reglamento, de acuerdo con la tipificación que en el mismo se establece» (8).

(8) El número 2 del artículo 53 del mismo Reglamento especifica algunas infracciones urbanísticas, pero sin demasiada precisión, incluso parece hacer equivalente «infracción urbanística» a "vulneración del ordenamiento jurídico». "De acuerdo con lo dispuesto en el número anterior-dice-, se considerarán infracciones urbanísticas:

a) La vulneración del ordenamiento urbanístico en el otorgamiento de una licencia u orden de ejecución. 
En la Ley del Suelo falta la tipicidad de las infracciones urbanísticas y en el Reglamento de Disciplina Urbanística también, aunque el artículo citado hable de la «tipificación que en el mismo se establece».

La Ley del Suelo, en su artículo 226,1 y 2, dispone que «las infracciones urbanísticas se clasificarán en graves y leves en la forma que reglamentariamente se determine. Tendrán, en principio, carácter de graves las infracciones que constituyan incumplimiento de las normas relativas a parcelaciones, uso del suelo, altura, volumen y situación de las edificaciones y ocupación permitida de la superficie de las parcelas». El artículo 228, 2, tipifica como falta, que debe ser sancionada con multa, el otorgar «una licencia cuyo contenido sea manifiestamente constitutivo de una infracción urbanística grave».

El artículo 54, 2 y 3, del Reglamento de Disciplina Urbanística declara que «son infracciones graves las acciones $u$ omisiones que, quebrantando el ordenamiento urbanístico, afectan a los bienes e intereses protegidos por el mismo, causándoles un daño directo y de importancia o creando un riesgo cierto e igualmente importante.

Tendrán el carácter de graves las infracciones que constituyan incumplimiento de las normas sobre parcelaciones, uso del suelo, altura, volumen y situación de las edificaciones y ocupación permitida de la superficie de las parcelas, salvo que en el expediente sancionador se demuestre la escasa entidad del daño producido a los intereses generales, o del riesgo creado en relación con los mismos».

Como acabamos de ver, el artículo 54 del Reglamento de Disciplina Urbanística, incumpliendo el mandato del artículo 226, 1, de la Ley del Suelo, que le ordenaba determinar las infracciones que debían considerarse graves y leves, emplea una fórmula genérica y no determinante. "Son infracciones (urbanísticas) graves - dicelas acciones u omisiones que, quebrantando el ordenamiento urbanístico, afectan a los bienes e intereses protegidos por el mismo, causándoles un daño directo y de importancia o creando un riesgo cierto $e$ igualmente importante».

Se traslada, pues, prácticamente, a los técnicos la determinación de cuándo el quebrantamiento del ordenamiento jurídico es grave

b) Las actuaciones que, estando sujetas a licencia u otra autorización administrativa de carácter urbanístico, se realicen sin ella, sean o no legalizables en atención a su conformidad o disconformidad con la normativa urbanística aplicable.

c) Las actuaciones que se realicen en contra de las determinaciones de la licencia, orden de ejecución o autorización administrativa de carácter urbanístico». 
o leve e incluso la Ley parece que quiere que sean ellos los que digan si se ha cometido o no una infracción urbanística. El informe de éstos, en cada caso, sobre si la acción u omisión ha causado un daño directo o de importancia o ha creado un riesgo cierto e igualmente importante, o bien que tiene escasa entidad el daño causado o el riesgo creado a los intereses generales, pero que se trata del incumplimiento de las normas sobre parcelaciones, uso del suelo, altura, volumen y situación de las edificaciones y ocupación permitida de la superficie de las parcelas, parece que decidirá si existe o no falta urbanística. Esto es discutible. Pero de lo que no cabe duda es de que en todo procedimiento de suspensión de una licencia de obras, iniciado después de haber transcurrido un año contado a partir de la notificación o publicación de la misma, será necesario, primero, un dictamen técnico sobre las características del daño y, segundo, una decisión municipal que considere que el quebrantamiento del ordenamiento urbanístico es una infracción urbanística grave, pues ésta es la única causa que puede justificar dicha suspensión. Después se podrá acordar la suspensión de la licencia.

La pregunta que ahora debemos formularnos es la siguiente: La autoridad municipal a quien corresponde suspender la licencia, ¿puede o debe hacerlo siempre que disponga de un informe técnico en el que conste que el daño producido por aquélla reúne las características que he recordado? En otras palabras, ¿existe infracción o falta urbanística grave siempre que el daño causado sea directo, o de importancia, o se haya creado un riesgo cierto e importante, o bien se incumplan las normas sobre parcelaciones, uso del suelo, altura, volumen, situación de las edificaciones y ocupación permitida de la superficie de las parcelas? Pienso que no, porque, repito, la infracción urbanística es una falta administrativa y, como ha dicho muchísimas veces la jurisprudencia, las faltas penales y las administrativas responden a unos mismos principios. Estos principios, según dice la Sentencia de 25 de marzo de 1972, Sala Cuarta (Aranzadi 1.472), son que "la acción ha de ser típica o prevista y descrita como tal por norma jurídica anterior, antijurídica, esto es, lesiva de un bien protegido por la Ley, culpable o atribuible al autor por dolo o culpa, y no procediendo en ningún caso la interpretación extensiva ni analógica, sino que es menester atenerse a la norma estricta». Por eso, como dice la Sentencia de 29 de mayo de 1964, «la imposición de una sanción implica siempre la necesidad del incumplimiento voluntario de una norma», porque sólo por la voluntad, añadimos 
nosotros, el hombre puede incurrir en dolo o culpa. Y la Sentencia últimamente citada añade: «Una interpretación razonada, aunque pueda ser equivocada, no se estima motivo suficiente para la sanción». La equivocación al cumplir una norma no es una falta (9).

Además, el contenido de la licencia debe constituir manifiestamente una infracción urbanística grave. La expresión infracción manifiesta o manifiesta infracción, ya la habían empleado otros preceptos legales anteriores al citado artículo de la vigente Ley del Suelo. Para interpretar el sentido del término "manifiesto", nuestro Tribunal Supremo acudió al Diccionario de la Real Academia de la Lengua. Este explica la significación de dicho adjetivo con estas tres palabras: descubierto, patente, claro. La Sentencia (Sala Cuarta) de 26 de enero de 1961 dice que la violación de la norma sea manifiesta tanto quiere decir que sea "descubierta y patente, de suerte que aparezca por la mera confrontación del contenido del acto con el precepto que le regula, sin necesidad de acudir a la interpretación o la exégesis» (10).

Para suspender, pues, los efectos de una licencia de obras después de haber transcurrido un año contado desde su notificación o publicación, es necesario que al confrontar su contenido con las leyes $\mathrm{u}$ otras normas urbanísticas, pueda comprobarse de inmediato que aquél constituye una falta grave. Pero antes será necesario un informe técnico y una decisión municipal anterior o simultánea al acuerdo de suspensión en el que se declare que se ha cometido una infracción urbanística grave.

Mi propósito fundamental ha sido situar el artículo 186, 1, de la Ley del Suelo en relación con los otros preceptos de la propia Ley del Suelo y de la Ley de Régimen local que regulan la suspensión de acuerdos municipales. Y creo que puede concluirse que, como las licencias de obras son una especie de acto administrativo, su eficacia puede suspenderse, en primer lugar, por las causas y en el plazo que señala el artículo 362 de la Ley de Régimen local; en segundo lugar, si infringen manifiestamente normas urbanísticas, dentro del año siguiente a su notificación o publicación y, en tercer lugar, cuando su contenido constituya manifiestamente una falta urbanística grave, aun cuando haya transcurrido el año siguiente a su notificación

(9) Estos principios han sido matizados por muchas decisiones judicjales de las que ahora no podemos ocuparnos. Pueden verse las Sentencias de 18 de noviembre y 10 de diciembre de 1964; 27 de febrero y 26 de marzo de 1965.

(10) Véanse resumidas en la Sentencia de 3 de mayo de 1979 (Aranzadi 2.242) las dos tendencias jurisprudenciales sobre este punto. 
o publicación. Como aplicar el artículo 186, 1, de la Ley del Suelo presenta serias dificultades, siempre que se quiera suspender una licencia, si no ha transcurrido un año desde su notificación, los administradores deben acogerse al artículo 224 de la Ley del Suelo. Las licencias de obras y las órdenes de ejecución tienen dentro de los actos administrativos un régimen de suspensión extraordinariamente privilegiado. Sin embargo, cuando ha transcurrido un año contado a partir de su notificación o publicación, no debe olvidarse que la suspensión de las licencias exige el cumplimiento de unas condiciones especialmente rigurosas y equivocarse en este punto no será demasiado difícil y puede tener consecuencias extraordinariamente graves.

\section{LAS AUTORIDADES COMPETENTES PARA DECIDIR LA SUSPENSION DE LAS LICENCIAS}

El Alcalde, además de órgano municipal, es el Delegado del Gobierno en el término municipal, salvo en los casos exceptuados por Ley (artículo 59 de la Ley de Régimen local). La facultad de suspender licencias otorgadas por el Ayuntamiento Pleno o la Comisión Permanente, la Ley se la confiere al Alcalde en cuanto representante del Gobierno, por lo que sólo él puede ejercitar dicha facultad y en su ejercicio no puede sustituirle el Ayuntamiento aun cuando éste es el máximo órgano municipal. Pero, como la decisión de suspender una licencia de obras puede llevar implícitas graves consecuencias, los Alcaldes suelen buscar el amparo de un acuerdo del Ayuntamiento en Pleno antes de adoptar la decisión de suspensión o bien quieren que sea aquél el que suspenda la licencia. Este amparo sólo será político o moral; el Ayuntamiento no puede compartir la responsabilidad del Alcalde. Además, el Ayuntamiento no puede decidir en lugar del Alcalde, porque cada órgano administrativo tiene sus propias competencias y no pueden ejercerlas unos por otros si las leyes no lo permiten expresamente. En este caso las leyes no lo permiten. El Alcalde - insisto - tiene la facultad de suspender las licencias de obras por su condición de Delegado del Gobierno en el término municipal y no como órgano del Municipio. El Ayuntamiento no puede ejercitar competencias propias de un delegado del Estado (11).

(11) Lo expresado en el texto se puede reforzar si comparamos el artículo 186 y el artículo 187 de la LS. El artículo 187 de la Ley del Suelo, en su número 1. dice que «las licencias u órdenes de ejecución cuyo contenido constituya manifiestamente 
El número 2 del artículo 186 dice que «si el Gobernador civil, de oficio o a instancia del Delegado provincial del Ministerio de la Vivienda, apreciare que las obras que se realizan al amparo de una licencia $u$ orden de ejecución constituyen ese mismo tipo de infracción urbanística, lo pondrá en conocimiento de la Corporación municipal, a fin de que su Presidente proceda según lo prevenido en el número anterior. Si en el plazo de diez días el Presidente de la Corporación municipal no adoptase las medidas expresadas en dicho número, el Gobernador civil, de oficio, acordará la suspensión de los efectos de la licencia u orden de ejecución y la inmediata paralización de las obras». También podrán hacerlo los órganos competentes de los Entes autonómicos o preautonómicos.

El número 3 del artículo 186 manifiesta que, «en todo caso, la autoridad que acuerde la suspensión procederá, en el plazo de tres días, a dar traslado directo de dicho acuerdo a la Sala de lo Contencioso-administrativo competente, a los efectos prevenidos en los números 2 y siguientes del artículo 118 de la Ley de la Jurisdicción Contencioso-administrativa». La Sala dictará sentencia por la que levante la suspensión o se anule el acto a que la misma se refiere (artículo 118, 5, y artículo 366 de la Ley de Régimen local).

alguna de las infracciones urbanísticas graves definidas en esta Ley deberán ser revisadas dentro de los cuatro años desde la fecha de su expedición por la Corporación municipal que las otorgó a través de alguno de los procedimientos del artículo 110 de la Ley de Procedimiento administrativo, bien de oficio o a instancia del Gobernador civil, a solicitud, en su caso, del Delegado provincial del Ministerio de la Vivienda. La Corporación deberá acordar, cuando proceda. la demolición de las obras realizadas, todo ello sin perjuicio de las responsabilidades que sean exigibles conforme a lo dispuesto en esta Leys.

La simple lectura del artículo de la Ley del Suelo que acabamos de reproducir y la del artículo 186 de la misma Ley nos permite apreciar lo siguiente: El artículo 186 se refiere a licencias cuyas obras estén iniciadas pero no terminadas, o en vías de ejecución, mientras que el artículo 187 es de aplicación a las licencias que amparan «obras realizadas» o terminadas. Las primeras, según el artículo 186, las deberá suspender el Alcalde. quien dará cuenta de ello a la Sala de lo Contencioso-administrativo competente. Las segundas, según el artículo 187, las revisará la Corporación municipal que las otorgó por medio de alguno de los procedimientos del artículo 110 de Ja Ley de Procedimiento administrativo.

El artículo 34 del Reglamento de Disciplina Urbanística desarrolla el artículo 186 de la Ley del Suelo, y el artículo 36 del mismo Reglamento desarrolla el artículo 187 de dicha Ley. No creemos necesario reproducir aquí ambos preceptos reglamentarios; una rápida lectura de los mismos convence a cualquiera de lo que acabamos de decir.

En conclusión, los artículos 186 de la Ley del Suelo y 34 del Reglamento de Disciplina Urbanística confieren competencia al Alcalde para suspender las licencias de las obras iniciadas cuando se dan las circunstancias que en los mismos se establecen. El artículo 187 de la Ley del Suelo y el artículo 36 del Reglamento de Disciplina Urbanística otorgan competencia a la Corporación municipal o Ayuntamiento para revisar las licencias de obras realizadas cuando concurren las circunstancias que en los mismos se establecen. 


\section{RESPONSABILIDAD ADMINISTRATIVA DE QUIENES PARTICIPEN EN EL OTORGAMIENTO DE UNA LICENCIA QUE CONSTITUYA MANIFIESTAMENTE INFRACCION URBANISTICA GRAVE}

Téngase presente que suspender una licencia en aplicación del artículo 186, 1, de la Ley del Suelo significa acusar a alguien de haber cometido una falta grave. Este alguien será alguno o algunos de los que hayan intervenido en la concesión de la licencia. Los técnicos municipales, Arquitectos, Aparejadores o Arquitectos técnicos, habitualmente; el Secretario de la Corporación; el Alcalde y los Concejales. Por eso esta clase de suspensiones suelen florecer al cambiar los componentes de los órganos municipales.

Las faltas administrativas deben ser castigadas o sancionadas. El artículo 228, 2, de la Ley del Suelo dice que «en las obras amparadas en una licencia cuyo contenido sea manifiestamente constitutivo de una infracción urbanística grave serán igualmente sancionados con multa: el facultativo que hubiere informado favorablemente el proyecto y los miembros de la Corporación que hubiesen votado a favor del otorgamiento de la licencia sin el informe técnico previo, o cuando éste fuera desfavorable en razón de aquella infracción, o se hubiese hecho la advertencia de ilegalidad prevista en la legislación del régimen local». El artículo 226, 3, de la misma Ley contiene la declaración siguiente: "Las infracciones urbanísticas se sancionarán con arreglo a lo establecido en los artículos 133 y siguientes de la Ley de Procedimiento administrativo». Esto significa que para sancionar una infracción urbanística será necesario cumplir los siguientes trámites: $10^{\circ} \mathrm{El}$ órgano competente dictará providencia de incoación del procedimiento (artículo 134 de la Ley de Procedimiento administrativo) y en la misma nombrará un instructor del expediente y, en su caso, un secretario. Esta providencia se notificará al expedientado o expedientados (artículo 135 de la Ley de Procedimiento administrativo). $2 .^{\circ} \mathrm{El}$ instructor ordenará la práctica de cuantas pruebas y actuaciones conduzcan al esclarecimiento de los hechos y a determinar las responsabilidades susceptibles de sanción (artículo 136, 1, de la Ley de Procedimiento administrativo). $3^{\circ}$ El instructor formulará un pliego de cargos (artículo 136, 2, de la Ley de Procedimiento administrativo) y se concederá a los interesados un plazo de ocho días para que contesten el pliego de cargos (artículo 136, 3, de la LP). 4. El instructor formulará propuesta 
de resolución y la notificará a los interesados para que aleguen cuanto consideren conveniente a su defensa (artículo 137, 1, de la LP). 5. La propuesta se remitirá con todo lo actuado al órgano que ordenó la iniciación del expediente para su resolución (artículo 137, 2, de la LP).

Otorgar una licencia cuyo contenido sea manifiestamente constitutivo de una infracción urbanística grave será una infracción urbanística que deberá ser sancionada con multa. Por consiguiente, averiguar si se ha cometido esta falta administrativa y quién o quiénes son sus responsables habrá de llevarse a cabo mediante el procedimiento brevemente recordado. No puede, pues, acordarse que una licencia tiene un contenido manifiestamente constitutivo de una infracción urbanística grave sin decidir, simultáneamente, después de seguir dicho procedimiento, quién o quiénes son los responsables de su otorgamiento.

\section{RESPONSABILIDAD POR LOS DAÑOS O PERJUICIOS QUE OCASIONE LA SUSPENSION DE LOS EFECTOS DE LAS LICENCIAS}

La paralización de obras en ejecución, como consecuencia de la suspensión de la licencia otorgada para su construcción, siempre origina, en mayor o menor grado, perjuicios a los constructores. Deterioro de la parte de obra ejecutada, gastos de conservación, aumento en muchos casos del precio de materiales y mano de obra, inmovilización de lo invertido, créditos obtenidos cuyo plazo de devolución corre sin rendir fruto, retraso en las ventas, etc. La Administración local que suspende una licencia de obras, ¿está obligada a reparar los daños y perjuicios que dicha suspensión puede originar al constructor de la obra?

El artículo 232 de la Ley del Suelo, único en el capítulo tercero de su título VII, bajo el epígrafe "Responsabilidad de la Administración", declara que «la procedencia de indemnización por causa de anulación de una licencia en vía administrativa o contencioso-administrativa se determinará conforme a las normas que regulan con carácter general la responsabilidad de la Administración. En ningún caso habrá lugar a indemnización si existe dolo, culpa o negligencia graves imputables al perjudicado».

La norma que con carácter general regula la responsabilidad de la Administración local es el artículo 121, 1, de la Ley de Expropia- 
ción forzosa. Este precepto proclama que «dará lugar a indemnización... toda lesión que los particulares sufran en los bienes y derechos..., siempre que aquélla sea consecuencia del funcionamiento normal o anormal de los servicios públicos, ... sin perjuicio de las responsabilidades que la Administración pueda exigir de sus funcionarios con tal motivo".

Una de las primeras interpretaciones del artículo 121 de la Ley de Expropiación forzosa (12) llegaba a la conclusión de que este precepto establecía un principio de responsabilidad objetiva aplicable tanto a la actuación material (hechos) de la Administración pública como a su actuación jurídica (actos administrativos) legal o ilegal. Dicho principio podía formularse así: La Administración pública debe reparar todo daño o perjuicio que cause a los administrados.

Pero cabía una interpretación distinta a la expuesta del artículo 121 de la Ley de Expropiación forzosa, especialmente de la expresión «servicios públicos». Esta podía entenderse en su sentido orgánico. Los servicios públicos como los componentes de la organización administrativa. La Administración respondería cuando su organización y actuación material, normal o anormal, no su actividad jurídica, causaran una lesión a los administrados. Esta interpretación sería, además, congruente con la preocupación tradicional y más habitual por la reparación de los daños y perjuicios causados por la Administración. La muerte o lesiones de un viandante por la carretilla de una instalación industrial del Estado, los daños causados por la explosión de un polvorín del Ejército, el desbordamiento de un río por la acumulación de materiales para construir un puente, etc., son la clase de daños cuya reparación por la Administración ha preocupado siempre. De los perjuicios que una sanción causa al sancionado, una liquidación de impuestos mal practicada al contribuyente, una licencia de obras anulada a un constructor, etc., nadie se había preocupado. Si la sanción, la liquidación o la anulación de la licencia son legales, a nadie se le había ocurrido siquiera que de estos actos legales de la Administración pudiera derivar responsabilidad nara ésta aunaue periudicasen al particular.

La interpretación de los términos en el sentido expuesto tenía el inconveniente de que el esfuerzo hecho por los autores de la Ley

(12) García dE Enterría, E.: Los principios de la nueva Ley de Expropiación forzosa, I. E. P., Madrid, 1956, págs. 174 y ss., y 200 y ss. 
de Expropiación forzosa para alcanzar la cima del Estado de Derecho, pues tal se considera la instauración de un principio de responsabilidad por los daños que éste cause, dejaba sin resolver el problema de la responsabilidad de la Administración por perjuicios derivados de sus actos administrativos. Quizá por esto la Ley de Régimen Jurídico de la Administración del Estado de 26 de julio de 1957, en su artículo 40, 1 y 2, sin modificar la regla básica de la Ley de Expropiación forzosa, quiso matizar su forma de aplicación y dijo que, aun cuando los particulares sufran en cualquiera de sus bienes y derechos un daño efectivo, evaluable económicamente e individualizado, como consecuencia de un acto administrativo, «la simple anulación en vía administrativa o por los Tribunales contenciosos de las resoluciones administrativas, no presupone derecho a indemnización». Lo cual equivale a decir que no todo daño producido por un acto administrativo ilegal origina el deber de la Administración de indemnizarlo, y no se alude de ningún modo al daño producido por un acto legal.

Las declaraciones legales pueden ser generosamente interpretadas por los autores, pero los Jueces, en su dura y difícil tarea de procurar hacer justicia en cada uno de los casos que resuelven, contemplan la realidad tan de cerca y ésta es tan variada que necesariamente tienen que establecer distinciones que el legislador a veces ni siquiera insinúa y que algunos autores creen que no es necesario tomar en consideración (por ejemplo, la distinción entre daños queridos directamente y los daños incidentales; daños ocasionados por hechos o actuaciones materiales y daños derivados de actos juridicos; daños causados por actos administrativos legales y daños producidos por actos administrativos ilegales; daños causados por malicia, culpa o negligencia, y daños causados sin poder ser imputados a una conducta inconveniente del causante). Distinciones que, en algunas ocasiones, la doctrina ha considerado trabas y obstáculos al reconocimiento de la responsabilidad de la Administración.

Lo que hoy resulta evidente, al cabo de unos años de experiencia en la aplicación del artículo 121 de la Ley de Expropiación forzosa y del artículo 40 de la Ley de Régimen Jurídico de la Administración del Estado, es la imposibilidad de dar un tratamiento unitario a la responsabilidad de la Administración, es decir, sin distinguir al menos los daños causados por sus hechos o actuaciones materiales y por sus actos administrativos. 
Recientemente, Blasco Esteve (13) ha puesto de relieve la singularidad de la responsabilidad por los daños o perjuicios que son consecuencia de actos administrativos. Dicho autor se muestra contrario a tal singularidad, pero no cabe duda de que sería necesario estudiar detenidamente las peculiaridades de la misma para dar una contestación adecuada a la cuestión de cuándo la Administración pública debe responder por los daños o perjuicios que ocasione la suspensión de los efectos de las licencias, o si debe hacerlo en todo caso. Esto nos exigiría estudiar problemas un tanto alejados del que inicialmente nos habíamos propuesto, por lo que debemos dejarlo para otra ocasión. Los datos jurisprudenciales más significativos pueden encontrarse en el citado trabajo de Blasco Esteve, y me parece que debo recordar, por la relación que guarda con el tema principal que me ha ocupado, la Sentencia de 3 de enero de 1979 (Rep. Aranzadi, núm. marg. 7), que dice que «cuando la lesión o el perjuicio existen y además el acto de la Administración es manifiestamente contrario a derecho, debe imputarse ese daño a la Administración, puesto que existe una relación directa entre el acto impugnado y el perjuicio o daño sufrido" (*).

(13) «La responsabilidad de la Administración por los daños causados por actos administrativos: Doctrina jurisprudencial», Revista de Administración Pública, número 91 , enero-abril 1980 , págs. 195 y ss.

(*) El Decreto-ley de 16 de enero de 1981, número 3/81, publicado en el Boletín Oficial del Estado de 31 de enero de 1981, en su artículo $8 .^{\circ}$, ha dispuesto que "la Administración del Estado sólo podrá suspender aquellos actos y acuerdos de las Corporaciones locales en los que concurran las siguientes circunstancias: a) Que afecten directamente a materias de la competencia del Estado. b) Que constituyan infracción de las leyes». Estas facultades «corresponderán a las Comunidades Autónomas, en relación con las competencias que hayan asumido...» 